DOI 10.1515/linpo-2017-0006

\title{
Manuel Castells' theory of information society as media theory
}

\author{
Kęstas Kirtiklis \\ Faculty of Philosophy, Vilnius University \\ kestutis.kirtiklis@ffsf.vu.lt
}

\begin{abstract}
Kęstas Kirtiklis. Manuel Castells' theory of information society as media theory. The Poznan Society for the Advancement of the Arts and Sciences, PL ISSN 0079-4740, pp. 65-77

The present article deals with one of the most elaborated theories of information society, proposed by Manuel Castells. Castells defines the present social landscape as the Information Age, in which human societies perform their activities in a new technological paradigm and argues that this landscape was brought about by the revolution of information and communication technologies (ICT) at the second half of the 20th century. I argue that Castells first and foremost theorizes these new ICT (in the vein of media theorist Marshall McLuhan) and discerns their three main features - network logic, timeless time and space of flows which are visible only in the interaction of media and society. Therefore, Castells' ICT / media theory serves as a kind of methodological framework for his theory of the information society.
\end{abstract}

Keywords: theories of information society, media theory, Manuel Castells, Marshall McLuhan, network logic, timeless time, space of flows

\section{Introduction}

It will not be an over exaggeration to state that the discourse of information society lost its momentum - it went out of intellectual fashion as well as political agenda and gave its place to the visions of the creative and / or smart society. Although the critics, who looked at the theories of the information society suspiciously as ideological constructs, created for political decisions, rather than instruments for understanding the social reality we lived and still live in (Ampuja \& Koivisto 2014; Garnham \& Fuchs 2014) may now appear right, these theories should not be thrown out into the dump of history, as the things which are of no theoretical interest anymore. They are worth studying not only as a chapter of intellectual history, as an example of a particular Zeitgeist which dominated the last years of the second millennium, but also meta-theoretically, as a recent ambitious theoretical attempt to explain the sum total of changes which took place in last decades. The present situation after the-information-society-boom creates a temporal distance and puts the researcher into a rather advantageous position, when the meta-the- 
oretical research on theories of information society deals with relatively completed discourse formation.

Since the range of theories on this topic is wide and importance of each particular theory varies greatly, out of the variety of theorists I have chosen Manuel Castells - arguably one of the most renowned theorists of information society in general and one of the most renowned theorists whose work on the Information Age dealt not with a particular aspect of social reality (economics, politics, or culture), but with the whole of it. Although Castells is neither the first one to theorize information society, nor the author of the term itself, he is certainly the most prolific writer on this topic and popularizer of the term and the field, whose work was debated at academic forums and whose influence reached far beyond the boundaries of academia, for Castells was and still is an advisor to many NGOs and governments.

It seems that in academia Castells' voluminous works were praised (Webster 2006), as well as disparaged (Abell \& Reyniers 2000) mainly for the use of empirical data - the admirers pointed to its vastness, whereas the critics accused Castells of a selective and eclectic use of it (Webster \& Dimitriou 2004, particularly vols. 2 and 3 for the debates on information society). But since my primary concern is the ways information society is theorized, I will side with the critics, who argue that Castells is rather vague about his theoretical and methodological position and the intellectual forerunners who influenced it (Fuller 1999; Ampuja 2010: 106).

At the beginning of his three-volume opus magnum The Information Age: Economy, Society, and Culture (originally published 1996-1998) Castells declares that "this is not a book about books", "it does not intend to discuss existing theories of post-industrialism or the information society" (Castells 2010 [1996]: 25). Moreover, elsewhere Castells declares that he seeks to provide a "grounded theory of the network society" (Castells 2000a: 5, 2009: 5), "distill theory from observation" (Castells 2000a: 6) which means that the data he got from observing the social world (or reading reports of observations made by his co-workers and other researchers) precedes and creates the theory. Therefore, he chooses not to discuss "the many important, and fruitful, theoretical contributions [...], which could anchor the categories and analyses" of information society (ibid.). These contribution, supposedly, would not add much to Castells' own findings, and surely will not add anything to the data, in which Castells is interested.

However, this is rather doubtful. Firstly, because Castells is famous for his general descriptions of the Zeitgeist and not that much for being an acute observer of details. Marko Ampuja notices that "it is beyond doubt that his [Castells] fame - especially in the general public world - is based on the imaginative concepts that he has produced as a contemporary diagnostician of society, rather than on his figures and tables or his own research" (Ampuja 2010: 106). And it is not completely clear how the crude worldly facts might suggest such concepts as timeless time, space of flows or even network society. The structure of The Information Age itself suggests that first (vol. 1) come Castells' theoretical insights, and only later the data (vol. 2 and 3) to support the theories.

Besides, Castells himself names a few theorists who influenced him: sociologists Touraine, Bell and Poulantzas (2010 [1996]: 25) and media and communication theorists Eco, Innis, McLuhan (whom he praises as a genius) (Castells in Rantanen 2005: 142). But 
what ideas did Castells borrow from them and what shape did they take in Castells' interpretation - these questions remain unanswered.

Thus, the present research focuses on one of Castells' intellectual forerunners - namely, Marshall McLuhan - and particularly on the influence of media theory on his theory of informational / network society - which is much less explored compared to the research of Castells' position in contemporary social theory (Webster 2006; Steinbicker 2001; Ampuja \& Koivisto 2014).

Not all Castells scholars envisage a direct continuity between the two thinkers. The similarities are undeniable. Philip Howard, in a book entitled Castells and the Media names McLuhan as one of the key influences on Castells (Howard 2011: 17-18) and states that Castells like McLuhan argued that "society cannot be understood without studying media technologies" (Howard 2011: 17), and that "in his study of the social impact of the internet, Castells makes some of the same observations that McLuhan made studying the impact of the television". However, according to Howard, "Castells probably uses more evidence, gathered in a more systematic way, than McLuhan" (Howard 2011: 18). Howard's scrappy remarks do not seem to prove or at least properly illustrate the influence of McLuhan on Castells, and Felix Stalder, on whose research Howard draws (Howard 2011: 9) might seem right to declare that "McLuhan's influence is more indirect than systematic" (Stalder 2006: 28).

Yet there are alternative opinions. For example, Ampuja (2010: 142) suggested that Castells borrowed from McLuhan the very idea of human social communication (and, respectively, cultural history) as a three-stage process: "The first one is the era of oral tradition, face-to-face communication and close-knit communities. The second stage starts with the invention of the phonetic alphabet, reaching full maturity with the diffusion of the printing press, books and newspapers. This "alphabetic order" is closely connected to the development of Western philosophy, cumulative science, rationality and hierarchical rule. After the era of literacy a third stage emerges, and this is the most important one for both McLuhan and Castells, especially as it contrasts sharply with the previous era". But then there is a question left open - what mechanisms, according to Castells and McLuhan lead to this kind and pattern of development?

The present paper addresses precisely this question. I will argue that McLuhan's influence on Castells is much bigger than Howard and Stalder suggested and that Castells follows the Canadian scholar in putting a much stronger emphasis on the media / information and communication technologies (ICT) and not on the society itself. Therefore, Castells first and foremost theorizes media (in the manner of McLuhan ${ }^{1}$ ) and then projects his media theory on society. In other words, for a long time Manuel Castells has been regarded as a social theorist, the present research suggests to reconsider him as media theorist.

${ }^{1}$ And this, curiously, makes Castells a participant of McLuhan's "resurrection" in the 1990-ies, which was diagnosed by Meyrowitz (2003: 205-208). 


\section{Castells' conception of information society}

In The Information Age Castells announces the coming of the new stage of societal development. He calls it the Information Age / informationalism and believes that it comes after two previous stages - pre-industrialism and industrialism (Castells 2010 [1996]: 14). Informationalism differentiates from the previous industrial stage essentially: "each mode of development has a structurally determined performance principle around which technological processes are organized: industrialism is oriented toward economic growth, that is toward maximizing output; informationalism is oriented towards technological development, that is toward the accumulation of knowledge and towards higher levels of complexity in information processing" (Castells 2010 [1996]: 17). However, Castells believes, focusing on information processing and not on the output, increases the output even more: "while higher levels of knowledge may normally result in higher levels of output per unit of input, it is the pursuit of knowledge and information that characterizes the technological production function under informationalism" (Castells 2010 [1996]: 17). Therefore, according to Castells, human / social development has a direction and this direction seems to be towards effectiveness. Each following stage surpasses the previous in effectiveness of performance.

How is this rise of effectiveness achieved? Firstly, as already quoted, through technological development, or, more precisely, through the transformations of the technological paradigm. Castells argues that the Information Age is "a historical period in which human societies perform their activities in a technological paradigm constituted around microelectronics-based information / communication technologies, and genetic engineering" (Castells 2000a: 5-6). It means that nowadays all the technologies, from ICT to genetic engineering ("the information technology of living matter" as Castells (2000b: 693) calls it) basically process information. This leads Castells to the conclusion that, in terms of information, the differences between contemporary society and its earlier stages are not merely quantitative (nowadays it is much more information in the social world), but qualitative (information plays a different role in contemporary society than it used to). To explain his position further Castells introduces a distinction between information society and informational society (Castells 2010 [1996]: 21):

The term "information society" emphasizes the role of information in society. But I argue that information, in its broadest sense, e.g. as communication of knowledge, has been critical in all societies, including medieval Europe which was culturally structured, and to some extent unified, around scholasticism, that is, by and large an intellectual framework. In contrast, the term "informational" indicates the attribute of a specific form of social organization in which information generation, processing, and transmission become the fundamental sources of productivity and power because of new technological conditions emerging in this historical period.

Thus, contemporary society might reasonably be called "informational", because information is the main source of productivity - the main product as well as the main means of production. However, throughout all of his opus magnum, Castells uses the epithet "informational" mostly for some realms of the social world (informational economy, politics, labor force, etc.), whereas for the whole of society he mostly uses the term 
network society. Surely the name comes from Castells' awareness that network logic is another key characteristic of the new form of society (Castells 2000a: 9-10; 2010 [1996]: 21). But where does this logic come from? Here once again the answer lies in technology, because it is precisely information processing technologies which "allow the formation of new forms of social organization and social interaction along electronically based information networks" (Castells 2000b: 693). Thus, the whole structure of society, according to Castells, is centered on the technologies, or, even, "technology is society" (Castells 2000a: 5) and one cannot understand society without technology (and vice versa).

But how does technology help us to understand the society?

In order to answer this question let me sum up briefly what was already said: contemporary of society is a product of the process of social development; it differs from the earlier stages in the effectiveness of performance. This effectiveness is achieved due to the transformation of the dominant technological paradigm - from matter-processing - to information-processing. Moreover, the new technologies not only increase the potential of society, but also (re)shape its structure according to the principle of their own performance. Does it mean that Castells believes that technology is a driving force of social development? This would lead to accusing Castells of technological determinism - an accusation Castells explicitly denies (Castells 2010 [1996]: 5-13). It is not worthy to hasten to condemn Castells, yet the merger of technology and society in his theory raises some important questions.

Firstly, how should the reader react to multiple passages where Castells urges as a first step of theorizing to "treat technology seriously, using it as the point of departure of this inquiry" (Castells 2010 [1996]: 4); and calls the "new technological paradigm" the first dimension of social change (Castells 2000b: 693; 2000a: 9; 2010 [1996]: XLIV; 2010 [1996], ch. 1)? If this does not mean that technologies determine the development of society, what then does it mean?

Secondly, Castells (2000a: 15) admits that "networks are very old forms of social organization". But then he adds that the networks "have taken on a new life in the Information Age by becoming information networks, powered by new information technologies" (ibid.). However, if the newness of the new form of society comes not in the society itself, but from the impact new technologies, and the direct impact of technology on society is denied, what kind of theorizing does that presuppose?

Therefore, I will further argue that in his theory of information society Castells in fact theorizes the new ICT and the main characteristics of Castells' network society - not only the network logic, but also timeless time and space of flows - are, in fact, the characteristics of the new ICT, which Castells borrows from McLuhan's media theory, and projects on the contemporary society. Further, I will discuss McLuhan's idea of the media, then I will turn to its reception in Castells' theory and finally I will make a few comments on the projection of the characteristics of the ICT on society. 


\section{McLuhan's media theory}

According to the accepted view Marshal McLuhan (and the so-called Toronto school of media research) turned the attention of communication scholars from media contents and audiences to the media itself. But what are the media? In the subtitle of his opus magnum Understanding media (1994 [1964]) McLuhan defined media in rather idiosyncratic way - as "the extensions of man". ${ }^{2}$ However, his best known definition of the media is a famous dictum "medium is the message" (McLuhan 1994 [1964]: 7). This leads the reader to think about the media in terms of classic media and information studies, as if media had only the "basic function [...] - to store and to expedite information" (McLuhan 1994 [1964]: 158).

Castells, apparently, gives in to this temptation, and prefers to discuss McLuhan's notion of the media (and respectively McLuhan's influence) in terms of communication / information, declaring that his theory overturns the McLuhanian approach: the changing modes of communication call for the development of the media (Castells 2010 [1996]: XXXVII) and "the characteristics of the message will shape the characteristics of the medium" (Castells 2010 [1996]: 368). According to Castells McLuhan was right in the era of mass communication, "the McLuhan Galaxy was a world of one-way communication", however, his theory does not capture the present situation of interactive communication (Castells 2010 [1996]: 370-371).

The problem here is that McLuhan has a rather different idea of the message than most of his readers. Surely, the message has some connection to the information, but this connection is particularly strong in the culture where writing is the dominant medium and the human interacts with the written media as if interacting with the author of a written text (McLuhan 1962: 78-79). But generally "the "message" of any medium or technology is the change of scale or pace or pattern that it introduces into human affairs" (McLuhan 1994 [1964]: 8). Hence, the message is the effect of the technology on the space, time and structure of human activity.

Media history in McLuhan's view is a story of development of media forms, regardless of contents and "regardless of the specific purpose, to which the artifact is put" (Meyrowitz 2003: 197). Thus, human history might be seen as a process of media development and its consequences - the influence of media forms on humanity.

There have been three stages of development: the first stage of oral culture was later superseded by writing (including typography) culture and in the mid-20 $0^{\text {th }}$ century McLuhan felt to be the witness of the rise of a new electronic culture. ${ }^{3}$ All three types of the

${ }^{2}$ McLuhan generally does not make a distinction between media and other technologies. He uses the term media for anything that may serve as "extensions of man". Castells on his turn uses the term "media", but mostly for institutionalized forms of mass communication - newspapers, radio, TV, internet sites. Media for him are rather businesses than technologies of communication (Castells 2009: ch. 2; see also Howard 2011: 8). However, when Castells speaks about uses of information to process information (one of the main characteristics of contemporary society) he uses the term "technology". The present paper aims at showing that McLuhan's "media" and Castells' "technology" might be treated as synonymous terms.

${ }^{3}$ Sonja Yeh (2015: 126-134) in her detailed and careful analysis of McLuhan's media theory contradicts this received view of the three stages (e.g. presented in Meyrowitz 2003: 195-196). Yeh distinguishes four 
dominant media have respectively three types of messages, i.e. effects on space, time and the structure of human action.

The differences of time and space in different stages are highly visible. In the times of oral culture, people lived in a "simultaneous time" (McLuhan 1962: 56) and a "complex, organic interplay of spaces" (1962: 45). The medium of writing and especially its development into typography introduced linearity and sequences in perception of time and space: "the new time sense of typographic man is cinematic and sequential and pictorial" (1962: 241) and the interplay of spaces was translated into a single space (1962: $45)$. Because of the possibility to write down, to capture in the text the most incommensurable things, writing created in the West the "uniform time and uniform continuous space in which "cause" is efficient and sequential, and things move and happen on single planes and in successive order" (McLuhan 1962: 19). And "the uniformity and repeatability of print permeated the Renaissance with the idea of time and space as continuous measurable quantities" (McLuhan 1994 [1964]: 176). This idea had a huge impact not only on the rising Western sciences, but also on such diverse spheres as art, literature, geography, transportation, even economics and modes of production, because printed text "was the first uniformly repeatable commodity, the first assembly-line, and the first mass-production" (McLuhan 1962: 124).

The development of science and technology led to the immediate and enormous growth not only of knowledge, but also of power. The Western world was rapidly expanding (exploding, to use the McLuhanian terminology) - literally (connecting earlier distant places and bringing them into the one common space through nationalism and unification of countries and through the rise of the colonial system) as well as figuratively (through the increase of economic, military, and intellectual power of the West).

However, in the mid-20 $0^{\text {th }}$ century McLuhan diagnoses a major shift in perception of time and space, since "after three thousand years of explosion, by means of fragmentary and mechanical technologies, the Western world is imploding" (McLuhan 1994 [1964]: 3). This implosion was caused by the advent of electricity and electronic media: "both time (as measured visually and segmentally) and space (as uniform, pictorial, and enclosed) disappear in the electronic age of instant information" (1994 [1964]: 138). This instantaneity "ends space as the main factor in social arrangements" (1994 [1964]: 94) and "plurality-of-times succeeds uniformity-of-time" (1994 [1964]: 152) - the world, apparently, is reverted back to the (pre-literate) village, but this time it is a "global village".

"Global village" not only means the end of time-space explosion, it also signifies the transformation of the structure of society, "our specialist and fragmented civilization of center-margin structure is suddenly experiencing an instantaneous reassembling of all its mechanized bits into an organic whole" (McLuhan 1994 [1964]: 93). The former center-margin structure vanished, because electricity and the electronic media are decen-

phases - Oral culture, Manuscript culture, Gutenberg-galaxy, Electronic age. However, the Manuscript culture in her analysis seems to be a transitional phase (cf. ibid. 187), between oral and printing cultures, rather closer to the Gutenberg-galaxy. For Yeh the leading medium of the oral phase is voice, for Manuscript culture - it is manuscript and writing, and for Gutenberg-galaxy - book and printing press - the difference of the latter two mainly lies in the extent of influence of the written media. 
tralizing (1994 [1964]: 36). Introduction of the new media, according to McLuhan (1994 [1964]: 64), affects not the area of social life where it was introduced, but the whole of society. Thus, the impact of the new electronic media was felt widely: not only in the fall of the colonial system of the world, but also in former metropolitan societies, where the variety of electronic media also challenged the unity created during the era of writing.

Therefore, decentralization poses the biggest civilization challenge to the whole contemporary Western world - economics, politics and culture should adapt to the challenge of the changing scale, pace and pattern of human activities, taking place at the new conditions of shrinking space and the new form of simultaneous time. This challenge, argues McLuhan, cannot be properly met and responded to by the good old hierarchical structure with the definite decision making center. It can only be adequately met by a qualitatively new response - "decentralism and the flexibility of multiple small centers" (McLuhan 1994 [1964]: 71).

To sum up: McLuhan describes the present social conditions using three characteristics, which essentially are spheres where media affect human activities: space, time and structure. All these elements nowadays experienced implosion - space lost its dependence on time and vice versa (i.e. to overcome the spatial distance humans do not need a lot of time anymore) and this led to a transformation of scale and pace of human activities, and, eventually, changed their whole pattern. The new media, in other words, brought about the new form of society.

Moreover, although McLuhan did not emphasize it, he acknowledged that with the advent of electrical technologies at least some parts of Western civilization (e.g. economic exchange) might be considered as "the movement of information itself" (McLuhan 1994 [1964]: 137) and the information itself has become "staples or natural resources" (1994 [1964]: 21; quoted in Castells 2010 [1996]: 362). And this is precisely the point where Castells' theorizing of information society starts.

\section{Castells' media theory}

Castells' believes that McLuhan's dictum "the medium is the message" could be adequately applied only in the world of mass media and mass communication (Castells in Rantanen 2005: 142). Thus, he explicitly tends to regard McLuhan merely a theorist of mid- $20^{\text {th }}$ century media and communication, whereas himself first and foremost $-\mathrm{a}$ theorist of contemporary society. Surely, the new ICT - internet, computers and recent smart gadgets - are not the media in the sense of one-to-many mass communication (Castells 2010 [1996]: XXVI; 2009: 63) calls it traditional sense); they are meant for many-tomany interactive communication.

However, Castells' attention to the new media and forms of communication as well as to the broader impact of technologies does not undermine McLuhan's general ideas about what the media are and how they work. Therefore, it seems that actually Castells inherited and further developed McLuhan's general attitude towards the media as the extensions of humans, conditioning the scope and effectiveness of their activities. For 
what in his theory are network logic, timeless time and space of flows, if not the "change of scale or pace or pattern introduced into human affairs" by the ICT?

It is evident for Castells that the media recently are undergoing the major change convergence and "the formation of a hypertext and a meta-language which, for the first time in history, integrate into the same system the written, oral, and audio-visual modalities of human communication" (Castells 2010 [1996]: 356). However, the new ICT system is integrated not as one and single unit, but as a network operating according to the particular network logic.

The protagonist of this media convergence and the contemporary arch-medium surely is the internet - a network of connected computers and servers in itself, which is able to connect and integrate the most incommensurable technologies and contents and to reconcile the multiplicity of communication patterns.

What is network? "A network is a set of interconnected nodes" (Castells 2000a: 15), networks are "patterns of contact that are created by the flow of messages among communicators through time and space. [...] Networks process flows. Flows are streams of information between nodes, circulating through the channels of connection between nodes" (Castells 2009: 20).

There are several important issues here. Firstly, Castells is quite explicit that the notion of networks comes from the realm of ICT. Secondly, the difference from mass media is the horizontality of networks: in the era of mass media information flows were linear and vertical from the privileged center to the periphery. Surely, not all nodes are equal, some of them become more important - they increase their importance by absorbing more information and processing it more efficiently (Castells 2009: 19). However, at the present age of decentralization "the main nodes are not centres, but switchers following a networking logic rather than a command logic" (Castells 2000a: 16). In other words, the main nodes of the network are not conductors or governors, but switchers of the networks, performing the operations of inclusion / exclusion.

Decentralization and the network structure of the media / ICT democratize communication: former receivers of the messages, transmitted through the media channels, nowadays are transformed into an active audience, thus they also should be considered to be nodes in the network, along with media institutions and technological objects (Castells 2009: 45). Thus, putting humans and technologies together Castells approaches the McLuhanian idea of the extension of humans through networking them.

The other two major transformations of contemporary technologies which had a social impact are concerning time and space.

The earlier Industrial Era had its own regime of time, Castells calls it "clock time". This time regime essentially differed from biological time of preindustrial societies, it was a mechanical time sequence, where human activities were measured not by biological rhythms, but by discreet time units. Industrial time reached its peak in Taylorism and the "scientific" organization of work, when the working time was measured to the smallest human movements in the assembly line.

Castells calls the dominant contemporary time regime timeless time. On the one hand it is a compressed time (as in instantaneous business transactions or long distance real time communicative interactions). On the other hand time is "de-sequenced, including 
past, present, and future occurring in a random sequence (as in the electronic hypertext [...])" (Castells 2000a: 14). Surely, both of these characteristics (instantaneity and de-sequentialization) come from the realm of contemporary ICT, which, in fact, enable both - instantaneous interactions as well as breaking of the time sequence. ${ }^{4}$

According to Castells these transformations of mediated time are incomprehensible without considering their impact on human activities. The social activities are so important because time itself is "a social form" (Castells 2010 [1996]: XLII), defined, in social terms, as "the sequencing of practices" (Castells 2009: 34).

The introduction of timeless time to society means "breaking down of the rhythms, either biological or social, associated with the notion of a life-cycle" (Castells 2010 [1996]: 476). And, surely, the timeless time is best felt in most ICT influenced spheres of social reality. However, Castells does not state that nowadays humans live solely in a timeless time. The transition from the biological or clock time to the timeless time is by no means finished. It is a gradual process of "systemic perturbation in the sequential order of the social practices" (Castells 2010 [1996]: XLI).

The perception of space undergoes the similar transformation - from the space of places (or, physical space, as it is usually called) to the space of flows. These two notions differ in relation to geography: "the space of flows refers to the technological and organizational possibility of organizing the simultaneity of social practices without geographical contiguity" (Castells 2000a: 13-14). Such a notion of space presupposes that "space is not a tangible reality" (Castells 2010 [1996] XXXI). However, it undeniably exists, because human activities should take place somewhere, even if this place cannot be geographically identified. Space of flows is not a place in a traditional sense (a locale whose form, function, and meaning are self-contained within the boundaries of physical contiguity" (Castells 2010 [1996]: 453)). Castells' space is not an absolute Newtonian space, it can be perceived only through the objects in it (Stalder 2006: 142), more precisely, only through the activities taking place in it. Thus, as in the case of the timeless time, space of flows "cannot be defined without reference to social practices" (Castells 2010 [1996]: 441). Therefore space of flows is the environment in which social practices take place; and with the help of ICT they might take place in real time in geographically distant places. Similarly to the case of timeless time, the expansion of the space of flows is a gradual process, spreading from most informationalized and mediated spheres to the rest of social reality

Actually, the space of flows is tightly knit to the timeless time and these two categories are unintelligible without each other. Castells (2010 [1996]: 441) explains: "space is the material support of time-sharing social practices. [...] By time-sharing social practices I refer to the fact that space brings together those practices that are simultaneous in time". From the point of view of traditional social theory social theory these practices

${ }^{4}$ Castells also has a more philosophical explanation for the timelessness of media time: contemporary ICT produce eternal (not subjected to obsolescence) as well as ephemeral (immaterial in a traditional sense, or rather e-material) content. These two characteristics make media / ICT content virtually timeless (Castells 2010 [1996]: 492). 
took place in geographically identifiable territories. Castells, on his turn, emphasizes their moving to the "nowhere" of virtual reality, caused by the influence of the new ICT.

\section{By way of conclusion: Media / ICT theory as social theory}

Castells not only emphasizes the influence of the new ICT on contemporary sociality, he focuses on this influence insomuch that his social theory is in fact the extrapolation of the theory of contemporary media into the realm of the social. This sheds some new light on the problem of the primacy of technology in Castells' picture of the social world.

Castells constantly emphasizes that the new technological paradigm is the primary dimension of social change (Castells 2000b: 693; 2000a: 9; 2010 [1996]: XLIV; 2010 [1996], ch. 1). This leads some critics to accuse him of technological determinism (Ampuja 2010: 144-147). Castells himself anticipated these accusations and vehemently denied them, right from the outset of his opus magnum declaring that "technology is society, and society cannot be understood or represented without its technological tools", moreover, "technology does not determine society: it embodies it." (Castells 2010 [1996]: 5). However, the analysis of Castells' key characteristics of information society suggested that despite this explicit statement, it is precisely au contraire: in Castells' perspective it is society which embodies technology, and Castells' perspective on society embodies his media theory.

Ampuja (2010: 111) is partly right, stating that for Castells all social and cultural change is essentially reduced to spatio-temporal change, underestimating other important features of the contemporary global capitalist socio-economic situation. Space and time are important for Castells, however, merely spatio-temporal transformations do not seem to be sufficient to explain the metamorphosis of the solid hierarchical industrial social structure into the flexible informational networks. Thus, network logic is undoubtedly the third essential element of Castells' theorizing, alongside with space and time. It might even be considered the most important element, for Castells suggests that it is the preceding element, "the emergence of a new social structure is linked to a redefinition of the material foundations of our life, of time and space" (Castells 2000a: 13).

Does Castells find these three elements in the social world, does he provide a "grounded theory of the network society" as he promises (Castells 2000a: 5, Castells 2009: 5)? As I hopefully already showed - certainly not!

Castells quite explicitly sees the whole of society in the image and likeness of the internet": "all processes are enacted by organizational forms that are built upon networks, or to be more specific, upon information networks" (Castells 2000a: 15). In other words, all contemporary flows - economic, financial, human, etc. - are identified and modelled by the patterns of the flows of information. And if the flows of information flow mostly

\footnotetext{
5 Moreover, Castells also pointed to the fact (2009: ch. 3) that the human mind is also based on networks - networks of neurons. This parallel between microcosm (the human) and macrocosm (the social world) somehow echoes McLuhan's idea that electronic technologies extend the human central nervous system into the world and connects it with the others (cf. McLuhan 1994 [1964]: 43).
} 
in the channels of the new ICT, then the flowing messages acquire the form and characteristics of the media - network logic, timeless time and space of flows.

Therefore, in the core of Castells theory of information society there is an ICT / media theory:

1. This media theory follows the theorizing vein of Marshall McLuhan, where media were perceived not as devices for communication, but rather as technologies which change the scale or pace or pattern of human affairs.

2. The conception of network logic takes on the McLuhanian idea of challenge of decentralization the electricity poses to the Western civilization. According to McLuhan the proper answer to his challenge is the decentralization of the former center-periphery structure of the social world, and Castells suggests that the contemporary networked ICT demand the networking of society.

3. Alongside network logic, two other important features of the new media are timeless time and the space of flows which follow McLuhan's theorizing of the implosion of time and space due to the change which replaced writing as a dominant medium by the electronic media.

Then, surely, to identify the coming of the new information (or, even, informational) society, Castells has to conceptualize the technological revolution, which not only caused the social transformation, but is visible in and can happen through the social transformations. In other words, Castells theorizes not the society itself, but the manifestations of transformations of the ICT in society.

\section{Acknowledgements}

This work was supported by the Research Council of Lithuania under Grant MIP-072/2014/LSS-250000-520.

\section{References}

Abell, Peter \& Reyniers, Diane. 2000. On the failure of social theory. British Journal of Sociology 51(4). 739-750.

Ampuja, Marko. 2010. The Media and the Academic Globalization Debate. Theoretical Analysis and Critique. Helsinki: Helsinki University. (Doctoral dissertation)

Ampuja, Marko \& Koivisto, Juha. 2014. From 'Post-Industrial' to 'Network Society' and Beyond: The Political Conjunctures and Current Crisis of Information Society Theory. tripleC 12(2). 447-463.

Castells, Manuel. 2000a. Materials for an exploratory theory of the network society. British Journal of Sociology 51(1). 5-24.

Castells, Manuel. 2000b. Toward a Sociology of the Network Society. Contemporary Sociology 29(5). 693-699.

Castells, Manuel. 2009. Communication Power. Oxford: Oxford University Press.

Castells, Manuel. 2010. The Information Age: Economy Society and Culture. Vol. I: The Rise of the Network Society. Second Edition with a new Preface. Malden, MA \& Oxford: Blackwell. (First published in 1996)

Fuller, Steve. 1999. The Information Age: Economy Society and Culture. Review Essay. Science, Technology, \& Human Values 24(1). 159-166.

Garnham, Nicholas \& Fuchs, Christian. 2014. Revisiting the Political Economy of Communication. tripleC 12(1). 102-141.

Howard, Philip N. 2011. Castells and the Media. Cambridge, UK \& Malden, MA: Polity Press. 
McLuhan, Marshall. 1962. The Gutenberg Galaxy. Toronto: University of Toronto Press.

McLuhan, Marshall. 1994. Understanding Media: The Extensions of Man. Cambridge, Massachusetts: The MIT Press. (First published in 1964)

Meyrowitz, Joshua. 2003. Canonic Anti-Text: Marshall McLuhan's Understanding Media. In Katz, Elihu \& Peters, John Durham \& Liebes, Tamar \& Orloff, Avril (eds.), Canonic Texts in Media Research: Are There Any? Should There Be? How About These?, 191-212. Cambridge, UK \& Malden, MA: Polity Press.

Rantanen, Terhi. 2005. The message is the medium. An interview with Manuel Castells. Global Media and Communication 1(2). 135-147.

Stalder, Felix. 2006. Manuel Castells. Cambridge, UK \& Malden, MA: Polity Press.

Steinbicker, Jochen. 2001. Zur Theorie der Informationsgesellschaft. Ein Vergleich der Ansätze von Peter Drucker, Daniel Bell und Manuel Castells. Wiesbaden: Springer Fachmedien.

Webster, Frank. 2006. Theories of Information Society. $3^{\text {rd }}$ Edition. London: Routledge.

Webster, Frank \& Dimitriou, Basil (eds.). 2004. Manuel Castells. Sage Series on Masters of Modern Social Thought, vols. 1-3. London: Sage.

Yeh, Sonja. 2015. Anything Goes? Postmoderne Medientheorien im Vergleich. Bielefeld: Transcript Verlag. 